\section{EMBRYRIDDLE}

Aeronautical University

SCHOLARLY COMMONS
Journal of Aviation/Aerospace

Education \& Research

Volume 4

Number 3 JAAER Spring 1994

Article 8

Spring 1994

\title{
Professional Pilot Studies: Proposed Content
}

Donald A. Petrin

John P. Young

Follow this and additional works at: https://commons.erau.edu/jaaer

\section{Scholarly Commons Citation}

Petrin, D. A., \& Young, J. P. (1994). Professional Pilot Studies: Proposed Content. Journal of Aviation/ Aerospace Education \& Research, 4(3). https://doi.org/10.15394/jaaer.1994.1134

This Article is brought to you for free and open access by the Journals at Scholarly Commons. It has been accepted for inclusion in Journal of Aviation/Aerospace Education \& Research by an authorized administrator of Scholarly Commons. For more information, please contact commons@erau.edu. 


\title{
PROFESSIONAL PILOT STUDIES: PROPOSED CONTENT
}

\author{
Donald A. Petrin and John P. Young
}

Professional pilot collegiate aviation curricula vary not only in depth of information, but also in topical content area. Although fundamental flight-related skills are clearly important, future graduates must be familiar with advances in automated cockpit technology and human factors. This article combines the observations of industry practitioners, recommendations of educators, guidelines of the Council on Aviation Accreditation, and the authors' opinions into proposed topic areas for four-year professional pilot curricula. Results of a 1993 preliminary study of collegiate professional pilot programs are included for comparison. It is hoped these suggestions will assist collegiate educators in developing, revising, and updating plans of study.

\section{INTRODUCTION}

Given the vigorous competition among pilot applicants for entry-level professional flying positions, it is imperative that students enrolled in post-secondary flight education programs receive comprehensive instruction in relevant career topics. Rapid, dramatic industry advances in cockpit displays, long-range navigation systems, and crew resource management issues necessitate timely professional pilot curricula.

This paper proposes content areas for an effective career pilot curriculum. Because general topic areas are discussed, it is not necessary that distinct courses be developed for each. However, curriculum designers should evaluate how each area fits into their overall program. For the purpose of this paper, collegiate professional pilot programs are assumed to prepare students primarily for airline or corporate pilot careers. The authors realize, however, that career pilots may enter other areas of specialization. To provide contrast with the elements of this proposal, a 1993 preliminary examination of aviation school professional pilot programs is included. It is important to recognize that proposed curriculum content areas represent the authors' recommendations based on shared perceptions and input from the following sources:

1. Current career/professional pilot course titles obtained from school catalogues.

2. Advisory panel members for a baccalaureate aviation degree program comprised of national/regional airline managers and pilots, corporate travel department managers and pilots, Federal Aviation Administration (FAA) representatives, and owners of fixed-base operations.

3. Council on Aviation Accreditation's Accreditation Standards Manual (1990), available from the University Aviation Association (UAA), Auburn, AL.

Summarizing the 1993 preliminary study, Table 1 lists generalized course titles of professional/career pilot curricula from school catalogues of responding twoand four-year aviation institutions listed in the Collegiate Aviation Directory (1989) published by the UAA. Since wide variability existed between titles and content, some of the unique, nontraditional titles were not listed separately, but instead were displayed as part of other, more common courses.

Wide variability was apparent among professional pilot curricula. Although all 26 respondents offered private, commercial, and instrument ratings, only 19 offered multi-engine instruction, 13 offered flight instructor preparation, and 11 offered instrument flight instructor courses. Only four of 26 offered any practical turboprop experience.

Four or less respondents offered instruction in the following areas: Multi-engine flight instructor; national airspace; human factors; performance of flight vehicles; flight engineer procedures; history of aviation; flight operations, weather, crew; transport category aircraft systems; high-performance flight crew; techniques; electronic navigation and flight; displays; multi-engine simulator, reciprocating; multi-engine simulator, turbine; 
Table 1

Survey of UAA Institutions Offering Professional Pilot Programs

\begin{tabular}{cl} 
Number Offering (out of 26) & \multicolumn{1}{c}{ Course/Topic } \\
\hline 26 & Private, Commercial, Instrument \\
22 & Aviation Meteorology \\
19 & Multi-Engine Airplane \\
19 & Small Aircraft Systems \\
18 & Powerplants \\
17 & Aerodynamics, Theory of Fight \\
13 & Aviation Safety \\
13 & Fight Instructor Airplane \\
11 & Instrument Flight Instructor \\
10 & Aviation Physiology \\
9 & Air Transportation \\
8 & Avionics \\
8 & Administration/Management \\
6 & Air Navigation \\
6 & Air Traffic Control \\
\hline
\end{tabular}

airline quality proficiency training; airport planning; dispatcher training; crew/air traffic control; integration; turbojet flight experience.

Clearly, the expectation for professional pilot graduates differs greatly among institutions. What elements should make up an effective professional pilot program? At a minimum, program offerings beyond fundamental college courses, such as English, math, and physics, should include the following aviation-related content areas (not listed in any particular order of priority).

\section{FLIGHT CERTIFICATION}

Students must have the opportunity to obtain flight training in preparation for the private pilot certificate, commercial pilot certificate, and instrument rating. Since a multi-engine rating is a prerequisite for most entry-level professional piloting positions, except flight instructor, it too should be available. Flight training may be conducted in-house by the institution's faculty/instructional staff or through contract training with nearby fixed-base operators. When the latter method is used, it is important that the institution's faculty closely monitor instruction being given to ensure quality and uniformity among instructors.

Supplementary instruction in preparation for pilot certification should emphasize material required for each FAA written (for example, chart and approach plate interpretation and use, performance, regulations, weather, systems, aerodynamics/flight mechanics). Student performance and course content must exceed minimum standards of achievement. It is not enough to teach the test nor is it sufficient for students to barely achieve FAA knowledge assessment standards at the collegiate level.

\section{SIMULATION}

The use of simulators, flight training devices, and part task trainers is becoming increasingly important in aviation education. Colleges and universities are recognizing the value of operating these machines to maximize training dollars. Most schools currently integrate single-engine ground trainers into their flight curricula. FAR Part 61 allows the logging of 50 hours of simulator time toward the commercial certificate and 20 out of the 40 hours needed for the instrument rating. Additionally, FAR Part 141 permits substitution of ground trainer time for some flight time while completing the private and commercial certificates, and the instrument rating. Even though ground trainers have limitations, valuable transfer of learning does occur in an environment that is both nonthreatening and economical to maintain.

Strong consideration should be given to acquiring a multi-engine, multi-crew type simulator or ground trainer. Future aviation professionals operating in sophisticated airline and corporate cockpits require effective crew resource management skills, in addition to mastery of normal, abnormal, and emergency procedures. Advanced training devices with realistic cockpits can provide a controlled environment for acquiring exceptional proficiency operating complex equipment. Although video and computer simulations offer alternative training capabilities, hands-on instruction in a high-fidelity machine replicating the actual aircraft is particularly beneficial.

Instrument proficiency should include area 
departures, enroute navigation, area arrivals, holding, and instrument approaches into congested airspace, such as New York or Chicago. Realistic distractions, weather difficulties, and equipment malfunctions must also be incorporated. Proper communications, including standardized clearance shorthand and readback procedures, should be taught.

After proficiency is achieved with all engines operating, engine-out procedures may be introduced. Typically, students would begin training in the right seat as first officer, then move to the left seat as competence, leadership skills, and judgment improve. Evaluation criteria might parallel those required for the Airline Transport Pilot pilot certificate with top students meeting or exceeding ATP practical test standards.

Crew resource management training should focus on interpersonal communications to include verbal/nonverbal cues, checklist discipline, departure/arrival briefings, decision-making, situational awareness, and conflict resolution. Line-oriented flight training (LOFT), in which a crew begins a normal flight and later encounters one or more problems in real time, is extremely valuable for development of judgment. Flights may be videotaped, thus easing debriefing of crew interactive processes.

\section{LOW/HIGH ALTITUDE ATMOSPHERIC SCIENCE}

Coursework should exceed minimal knowledge required to pass FAA written tests. It is not enough to merely read charts or forecasts. Emphasis should be placed on how what is read affects the flight-making decision and how to analyze in-flight weather. High altitude meteorology should emphasize upper tropospheric weather phenomena and their relationship to both enroute flying and the development of synopticscale weather systems. Methods for detecting and avoiding severe weather such as thunderstorms or flight conditions resulting from hurricanes or other large-scale events must also be taught.

These methods should include the use and interpretation of radar and lightning-detection data (including National Weather Service products) and visible/ infrared satellite imagery. Finally, students should be introduced to Aviation Routine Weather Reports (METAR) and Terminal Aerodrome Forecasts (TAF), which will become fully implemented on Jan. 1, 1996.

\section{AIRCRAFT SYSTEMS}

Although it is necessary to understand small aircraft, including electrical, fuel, vacuum, oxygen, pressurization, and retractable gear systems, it is also important to gain a working knowledge of turboprop and turbojet aircraft systems. Corporate students might focus on business turboprops and turbojets (King Air, Citation, or Learjet), while airline majors would study transport aircraft (B-727, B-737, B-757/767, or Airbus 300 series). Mastery of these complex systems connotes an aptitude for moving on to similar aircraft commonly found in industry.

\section{POWERPLANTS}

It is important that students learn the theory of operation and design for four- and six-cylinder carbureted and fuel-injected reciprocating powerplants. Turbocharging, fixed-pitch and constant-speed propellers are commonly found on small aircraft, therefore, a module on each is necessary. Perhaps a brief module on multi-row radial engines would be appropriate because a few radial engine-powered transport aircraft are still in operation.

One powerplant module should focus entirely on turbine engine design and operation. Turbojet/turbofan development and theory of operation must be thoroughly examined. The Pratt and Whitney PT6 series or the Garrett TPE series are possible candidates for study because of their popularity with turboprop airframe manufacturers. Similarly, the General Electric CJ610, Pratt and Whitney JT15D, and Garrett TFE are excellent choices for the study of small turbojet/turbofan designs, commonly found on corporate jet aircraft.

Since large turbojet aircraft must also be studied, it is entirely appropriate to include modules on large turbojet engines such as those found on transport category Boeing, McDonnell Douglas, and Airbus aircraft. Normal, abnormal, and emergency warnings and operation should be emphasized.

\section{AVIONICS}

Professional pilot curricula must focus on the latest technologies for cockpit navigation and communication displays. Digital data entry and representation, including electronic flight information 
systems, flight management systems (Global GNS-X multi-navigational sensor) and collision avoidance (TCAS) are excellent topics. Students must have a background not only in common VOR/ADF displays, but also in inertial and laser navigation, long-range navigation (LORAN), VLF/Omega, and especially the Global Positioning System (GPS).

\section{HISTORY OF AIR TRANSPORTATION}

A solid foundation in history gives students insight into aviation origins, customs, and processes. Evolution of design strategies, airspace, regulations, history of the FAA, the Aviation Safety Reporting System (ASRS), and licensing are but a few of the major topic areas. Directed research into airline growth, deregulation, and changes that have occurred in aircraft and pilot certification promote understanding of the contemporary industry.

\section{AIRPORTS}

Professional aviators will operate out of domestic (and perhaps international) airports of varying complexity and design. It is imperative for flight students to recognize how site selection concerns, construction limitations, special interest groups, funding, and government regulations influence airport development and operation. An overview of how these (and other) critical factors affect airport planners' decision-making will assist students in articulating differences between airport designs.

\section{AVIATION LAW}

Given the litigious attitude toward aviation products (and activities) and the monumental financial consequences of perceived shortcomings, it is imperative that students possess rudimentary legal knowledge. Interest areas might include pilot certificate action, negligence, ownership, contracts, insurance, and taxation. Landmark court decisions using case-study models would emphasize how laws and regulations have evolved and add vitality to this study module.

\section{AVIATION BUSINESS}

Since professional aviators may be active in professional organizations or advance to senior captain, chief pilot, director of training, corporate vice president or higher, it is important they possess a background in business skills. Studying the global development of aviation to include market overview, outlook, and origins creates a solid foundation. Specific topic areas such as hiring, writing performance appraisals, termination, job counseling, theory of management, taxation, and federal law are extremely important.

\section{AVIATION SAFETY}

Aircraft and supporting equipment represent large dollar investments. Accidents may cause loss of life or equipment and result in lawsuits or insurance claims seeking huge sums of money. One way to minimize risk exposure is to study aviation safety. Accident causes, guidelines for safe operation, and pilot/owner responsibilities are examples of topic areas.

\section{HUMAN FACTORS/ \\ CREW RESOURCE MANAGEMENT}

Human factors and crew resource management have become increasingly relevant because of research into what previously had been labeled pilot-error accident. Recognizing distraction, pilot fatigue, low situational awareness, and poor flight-deck decisionmaking are useful learning outcomes for students. Psychological factors, judgment development, stress, conflict resolution, communications, and leadership/followership should also be included. Case studies, small group activities, accident re-enactments, synergy exercises, and role playing are valuable classroom techniques for teaching this material. Landmark general aviation, regional airline, and major air carrier accidents provide compelling discussion.

\section{AIR NAVIGATION}

Beyond fundamental VOR and ADF navigation, this topic should include practical training in inertial and laser navigation, LORAN, GPS, VLF/Omega and a discussion of flight management systems. The student must recognize the relationship between utility and legality of each system. Additionally, manual and computerized oceanic flight planning should be practiced. Examples of professional flight-planning services could be included.

\section{THEORY OF FLIGHT}

Knowledge of flight theory must surpass that needed to pass FAA written exams. Aerodynamics should encompass subsonic, transonic, and supersonic flight.

Performance characteristics and charts should be 
taught for light aircraft through heavy jet transport aircraft. Similarly, weight and balance computations, including weight shifting and mean aerodynamic chord problems, must be thoroughly taught for a variety of aircraft. Requiring students to first manually determine appropriate quantities and later use computerized equipment reinforces acquired skills. The references, charts, and questions in the FAA's ATP written test guide are helpful in establishing student competency areas.

\section{AIRMAN INFORMATION AND OPERATING RULES}

Thorough discussion and review throughout the curriculum will ensure that recommended normal and emergency operating procedures are followed under differing circumstances. This information, contained primarily in the Airman's Information Manual (AIM) and FARs, addresses VFR and IFR flight, and the new airspace system. Professional pilots must demonstrate mastery in each area. Since FARs are periodically altered, frequent review and updating is needed.

In addition to study of traditional FAR Parts 1, $61,91,135$, and NTSB 830 , typically in preparation for private, commercial, and instrument written exams, students must be familiar with the operating rules of Parts $63,91,121$, and 125 applicable to large aircraft or air carriers. Faculty can be encouraged to develop innovative ways of teaching regulations so that student interest is maintained.

\section{AVIATION PHYSIOLOGY}

Understanding the relationship between flight environmental factors and the human body is important for all pilots. Relevant topics include human anatomy, vision, hearing, altitude physiology, stress, fatigue, jet lag, health maintenance programs, and in-flight medical emergencies. Each student must be able to assess personal airworthiness before each flight.

AIR TRAFFIC CONTROL

Understanding the role of air traffic control as it applies to Visual Flight Rules and Instrument Flight Rules operations is an important aspect of every pilot's education. When pilot and controller responsibilities are well understood, the system operates more efficiently and, hopefully, with fewer errors. Where feasible, field trips to tower facilities and air route traffic control centers may be conducted.

Proper phraseology must be emphasized from the student's first day of flight training. The progression of communication skills from airports in class $G$ airspace to sophisticated instrument message transmission needed in classes A, B, or C airspace must become clear. Effective communication skills are crucial to success as a professional pilot.

\section{FLIGHT OPERATIONS}

Before graduation, the student should be exposed to the typical operational problems and conflicts of a professional pilot. Preflight planning using computerized software, scheduling, passenger service requirements, and line operating procedures are possible content areas. Familiarization with unions, collective bargaining strategies, furloughs, route and equipment assignments, drug testing, and other job-related activities will better prepare a student for the outside world. If the school's faculty does not have the expertise, guest speakers and field trips to airline and corporate facilities may be scheduled.

\section{ETHICS AND PROFESSIONALISM}

Students must recognize attributes of the professional aviator, including appropriate rules of conduct for dealing with others, accepting or rejecting employment offers, and discretion in personal affairs. Role playing and videotaping of practice behaviors are helpful classroom strategies.

\section{OPTIONAL AREAS}

Specialized, optional training might also be offered if resources and student interests permit.

Because the majority of flight graduates begin their aviation careers as certified flight instructors, professional pilot programs could offer flight instructor, instrument flight instructor, and multi-engine flight instructor certification. Unfortunately, not all pilots become competent instructors and substantial, perhaps irreparable damage to a fledgling student may result when an instructor's sole motive is to build hours toward a better job. Consequently, professional piloting majors should not be forced to obtain flight instructor certification by curriculum requirements.

Other specialized, optional areas (which, in some cases might lead to certification) could include aerobatic 
training, flight engineer training, dispatcher training, airplane type ratings, motor glider training, helicopter training, sea plane training, mountain flying/high density altitude procedures, glider training, or survival instruction.

When the educational institution uses aircraft for staff transportation, students can acquire valuable handson experience by serving as copilot. Some schools contract with airlines and other training organizations to offer students opportunities for specialized pilot training in state-of-the-art corporate and airline simulators.

Many aviation schools have instituted cooperative education programs and internships to provide their students with actual experience working in industry. Partnerships between the established company and the school can provide tangible benefits for both. With creativity and effort, each institution can provide unique learning opportunities for its students.

\section{CONCLUSION}

Based on a preliminary study of collegiate pilot programs, Council on Aviation Accreditation guidelines, and discussions with industry practitioners, the authors are convinced that these subject areas not only have merit in a four-year professional pilot curriculum, but also thoroughly prepare students for careers in aviation. Although integration of each topic into a plan of study encourages curriculum standardization, it is recognized that some institutions will not have the resources to include all elements. Perhaps a building block approach, adding courses as support becomes available, would be appropriate. Clearly the result can be nothing less than graduates who will be well prepared to serve in the cockpits of tomorrow's aircraft. $\square$

Donald A. Petrin earned an M.S. in Adult Education from Indiana University. He is an Associate Professor in the Professional Pilot program at Purdue University and he is chairman of the University Aviation Association Written Test Advisory Committee.

John P. Young holds an M.S. in Instructional Systems Technology from Indiana University. He is an Associate Professor in the Professional Pilot program at Purdue University. 